\title{
El negocio bancario en el punto de mira: ¿un nuevo paradigma?*
}

\author{
Cristina Ruza Paz-Curbera \\ Marta de la Cuesta González \\ Universidad Nacional de Educación a Distancia
}

\section{Resumen}

Este artículo analiza el negocio bancario más allá del enfoque tradicional de gestión de riesgos financieros, incidiendo también en el conjunto de riesgos que afectan a su imagen corporativa. Los consumidores, como usuarios últimos de los productos y servicios bancarios, han cobrado un especial protagonismo en los últimos tiempos y están ejerciendo un papel muy activo en defensa de sus intereses. En el artículo se examinan datos sobre el mecanismo de supervisión de entidades bancarias en España estructurado en dos niveles y se analiza el contexto y los principales retos a los que tienen que enfrentarse las entidades financieras en nuestro país.

Palabras clave: responsabilidad social corporativa, desarrollo financiero, conducta bancaria, reclamaciones bancarias, derechos de los consumidores.

Clasificación JEL: G21, O16.

\begin{abstract}
This article analyses banking business far beyond traditional risk management approaches. It will place special emphasis on risks that directly affect banks' corporate reputation. In the last years, consumers as ultimate users of banking products and services have been exerting particular power in defence of their interests. In this article we will analyse empirical data regarding the supervision mechanism in force in Spain, which is structured in two levels, and we will devote special attention to the context and the main challenges that financial entities in Spain will face in the near future.
\end{abstract}

Keywords: social corporate responsibility, financial development, banking behaviour, bank claims, consumer's rights.

JEL classification: 621,016 .

\section{Introducción}

La importancia del sistema financiero en la dinamización de la economía ha sido una cuestión ampliamente debatida en la literatura económica. El debate sobre la relación entre desarrollo financiero y crecimiento económico se remonta a principios del siglo xx con la obra de Schumpeter (1911), y a día de hoy existe consenso

* Este trabajo ha sido realizado en el marco del Proyecto Nacional I+D «El Tribunal de Justicia de la Unión Europea: su incidencia en la configuración normativa del proceso civil español y en la protección de los derechos fundamentales» (Ref. DER 2016-75567-R), financiado por el Ministerio de Economía y Competitividad y del que es investigadora principal Marien Aguilera. 
al señalar son los mercados y las instituciones financieras quienes tienen un papel decisivo a la hora de decidir en qué proyectos invertir, cuándo, en qué cantidad y a qué precio. Por tanto, su impacto global socioeconómico y ambiental es grande y muy superior al de otros sectores de actividad.

En los últimos tiempos son muchas las voces que han puesto en tela de juicio la capacidad del sistema financiero para desempeñar sus funciones de forma eficiente, así como la idoneidad y legitimidad de algunas de las prácticas bancarias en uso que, a la postre, están teniendo un elevado coste para el conjunto de la sociedad. Nos estamos refiriendo a los recientes escándalos financieros, de los que se han hecho eco las portadas de la prensa económica especializada y los principales medios de comunicación.

El presente artículo trata de analizar el comportamiento de la banca, no desde un punto de vista estrictamente financiero, sino que trata de ahondar en las consecuencias que el modelo de negocio bancario actual está generando, en particular sobre los clientes bancarios. Para ello analizaremos en el siguiente apartado los principales datos del negocio bancario visto desde la perspectiva del usuario, y la importancia del ente supervisor como garante último de sus derechos. El tercer apartado ofrece argumentos a favor de la incorporación de principios de responsabilidad social corporativa (RSC) en la práctica bancaria diaria, especialmente en el segmento de negocio minorista, identificando los principales riesgos extrafinancieros generados por este negocio. El artículo concluye con un apartado donde se recogen los principales retos y oportunidades para que el sector bancario pueda mejorar su reputación social y corporativa tan deteriorada en nuestros días.

\section{El negocio bancario desde el punto de vista de los usuarios}

Los intermediarios financieros en general y las entidades de depósito en particular, desempeñan un papel clave en el desarrollo económico y social de un país al tener capacidad de decisión sobre los proyectos de inversión a financiar, la gestión y diversificación de riesgos de sus carteras y, en definitiva, sobre el tipo de actividades y agentes económicos que reciben finalmente la financiación solicitada. A ello hay que sumar que para muchos individuos y empresas los préstamos bancarios constituyen la única vía de financiación a la que tienen acceso, puesto que los mercados de capitales se encuentran fuera de su alcance. Además de ser entidades importantes por razón de sus funciones, también son las entidades que reciben una mayor atención por parte de reguladores y supervisores. El motivo fundamental reside en la especial naturaleza y vulnerabilidad del sistema financiero en su conjunto ante situaciones de riesgo sistémico. 
En nuestro país las competencias del procedimiento supervisor son compartidas por el Banco de España ${ }^{1}$ (BE) y el Mecanismo Único de Supervisión. Dentro de las funciones desempeñadas por el BE existe un conjunto específico dedicado a la supervisión de conducta de entidades, cuyo objetivo último consiste en garantizar que las entidades bancarias salvaguardan los derechos de su clientela.

Desde 2015 es el Departamento de Conducta de Mercado y Reclamaciones (DCMR) del Banco de España quien ejerce de forma efectiva las competencias específicas de supervisión en nuestro país. Dentro de las competencias de supervisión que asume se encuentran las referidas a la comercialización de productos hipotecarios, dadas las especiales características que reviste este tipo de producto bancario. Nos referimos al gran calado que los créditos hipotecarios tienen en nuestro país, ya sea en términos del número de prestatarios hipotecarios como del volumen de préstamos concedidos. Asimismo, el dilatado plazo de vencimiento de este tipo de financiación implica una relación muy duradera en el tiempo entre el cliente y su entidad bancaria, con lo cual se hace necesaria una estricta supervisión.

Las tareas de los supervisores se han focalizado en verificar el adecuado cumplimiento de la Orden EHA/2899/2011, de 28 de octubre, de transparencia y protección del cliente de servicios bancarios sobre viviendas situadas en territorio español, otorgados a personas físicas residentes en España. No es de extrañar que esta materia haya acaparado gran parte de las actividades de supervisión puesto que, aproximadamente, la mitad de las reclamaciones recibidas por el departamento supervisor han versado sobre esta materia.

Un segundo bloque de actividades de supervisión se refieren al funcionamiento de los servicios de atención al cliente (SAC) y defensor del cliente (DC) de las entidades bancarias, pilares fundamentales del procedimiento supervisor en España que, de acuerdo con la Orden ECO734/2004, de 11 de marzo, se estructura en dos niveles. El SAC y el DC son los encargados de atender en primera instancia las reclamaciones presentadas por los clientes bancarios ${ }^{2}$. Posteriormente, si estos servicios no resuelven, o lo hacen de forma no satisfactoria para el cliente, este tiene potestad para presentar su reclamación ante el Departamento de Conducta de Mercado y Reclamaciones (DCMR) del BE. Bajo este esquema resulta indispensable que ambos niveles funcionen de forma eficiente para salvaguardar de forma efectiva los derechos fundamentales de los clientes bancarios ${ }^{3}$.

${ }^{1}$ En virtud de la Ley 10/2014, de 26 de junio, de ordenación, supervisión y solvencia de entidades de crédito, corresponde al Banco de España asumir la función supervisora de las entidades de crédito, de los grupos consolidables de entidades de crédito con matriz en España y de las sucursales de entidades de crédito de Estados no miembros de la Unión Europea.

${ }^{2}$ De acuerdo con la Orden ECO734/2004, estos servicios disponen de un plazo de dos meses para resolver.

3 Recuérdese que en el ámbito financiero existen problemas de información asimétrica entre prestamistas y prestatarios, tanto ex ante (selección adversa) como ex post (riesgo moral). Esta opacidad sitúa al cliente bancario en una posición de vulnerabilidad frente a su entidad financiera, de ahí que resulte tan importante la protección del consumidor bancario. 
Si analizamos los datos, en el Gráfico 1 se observa que el número de reclamaciones de clientes bancarios recibidas por el Banco de España en 2013 experimentó un importante salto cuantitativo y cualitativo. En este año se produjo un incremento más que notable del número de reclamaciones, que pasa de cerca de 15.000 reclamaciones en 2012 a rozar casi las 35.000 en $2013^{4}$. La gran mayoría de estas reclamaciones han versado sobre la inclusión de las denominadas «cláusulas suelo», que limitan la variabilidad del tipo de interés para financiación hipotecaria a tipo variable. El motivo que subyace a este cambio tan pronunciado es el pronunciamiento del Tribunal Supremo en la Sentencia del Tribunal Supremo 241/2013, Sala de lo Civil, de 9 de mayo de 2013, que establece que en el momento de la contratación de un producto hipotecario se debe cumplir el doble filtro de la normativa de «transparencia y protección a la clientela bancaria» y de las «condiciones generales de contratación», pero también que las entidades deben verificar que el cliente en cuestión ha comprendido el alcance y contenido de dichas cláusulas y las situaciones de riesgo en las que puede incurrir. Este concepto de «comprensibilidad real» por parte del consumidor ha generado no pocas dudas de interpretación y, en última instancia, son los tribunales los encargados de resolver en vía judicial la calificación de los hechos referidos a cada operación en concreto, y declarar o no la nulidad de dichas cláusulas. En este contexto, el papel del BE se ha limitado a verificar el cumplimiento formal de la mencionada normativa de protección de los intereses de los clientes $^{5}$.

Esta sentencia constituye, por tanto, un punto de inflexión que marca un antes y un después en el marco de seguridad jurídica referida a la comercialización de productos hipotecarios en nuestro país. A esta sentencia se unen varios hitos jurídicos recientes: Asuntos acumulados C-154/15, C-307/15y C-308/15, Sentencia del Tribunal de Justicia (Gran Sala), de 21 de diciembre de 2016 y el Asunto C-421/14, Banco Primus c. Jesús Gutiérrez García, Sentencia del Tribunal de Justicia (Sala Primera), de 26 de enero de 2017. La primera de estas sentencias establece la retroactividad de la aplicación de nulidad de las cláusulas suelo de los contratos hipotecarios con respecto a la fecha de la sentencia del Tribunal Supremo anteriormente mencionada de 9 de mayo de 2013. Ahondando en la materia, la sentencia de 26 de enero abunda aún más sobre el concepto de cláusulas abusivas y se pronuncia sobre las cláusulas de vencimiento anticipado, el cálculo de intereses ordinarios y sobre los contratos ya sometidos previamente a un control judicial, fijando criterios vinculantes para determinar si determinadas cláusulas contractuales son o no abusivas desde el punto de vista legal.

Si bien el número de reclamaciones presentadas es un buen indicador del nivel de satisfacción de los usuarios bancarios en general, conviene ahondar en los datos

${ }^{4}$ De acuerdo con el último dato disponible publicado por el Banco de España (Memoria de Reclamaciones de 2016 recién publicada), el número de reclamaciones presentadas en 2016 ha continuado la senda bajista iniciada en 2013, registrando en el último año un descenso del 28,6 por 100 (14.462 reclamaciones).

${ }^{5}$ De hecho, los informes emitidos por el DCMR no tienen carácter vinculante para las entidades involucradas. 


\section{GRÁFICO 1 \\ NÚMERO DE RECLAMACIONES PRESENTADAS ANTE EL BANCO DE ESPAÑA}

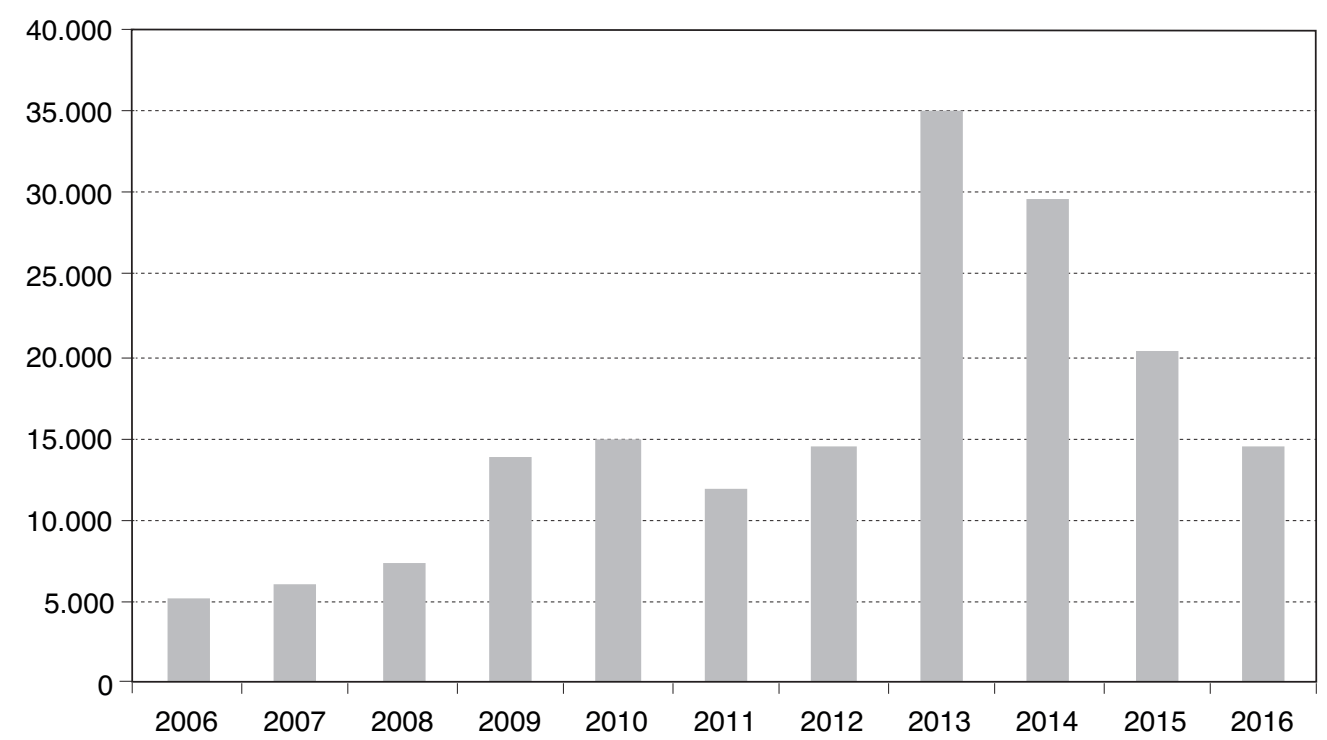

FUENTE: Banco de España (2015a).

y verificar la eficacia de nuestro sistema de supervisión estructurado, como ya se ha señalado, en dos niveles. De acuerdo con el BE (2015: 14) «un porcentaje elevado de informes favorables al reclamante indicaría que la entidad no ha resuelto adecuadamente la reclamación de sus clientes en su SAC, obligándoles a acudir al DCMR en busca de una resolución favorable a sus intereses».

En el Gráfico 2 se analiza el porcentaje de informes resueltos por el DCMR a favor del reclamante, y se observa que en los dos últimos años para los que tenemos datos disponibles, esta cifra se ha situado por encima del 60 por 100 . Este dato nos debería hacer reflexionar sobre el papel que desempeñan las entidades bancarias en la resolución de conflictos con sus clientes. Si un elevado número de expedientes se tramitan a través del Banco de España y, además, este resuelve a favor de los intereses de los reclamantes en un porcentaje muy elevado, entonces la pregunta que surge inmediatamente es: ¿están las entidades bancarias verdaderamente implicadas en la resolución de los conflictos que surgen con sus clientes o delegan esta responsabilidad en el criterio del DCMR? La evidencia demuestra que la tendencia ha sido a la delegación.

Antes de concluir este apartado nos vamos a detener a analizar algunos datos relativos al denominado Código de Buenas Prácticas (en adelante CBP), que recoge el anexo del Real Decreto-Ley 6/2012, de 9 de marzo, de medidas urgentes de 


\section{GRÁFICO 2}

\section{INFORMES FAVORABLES POR PARTE DEL DCMR AL CLIENTE}

(En \%)

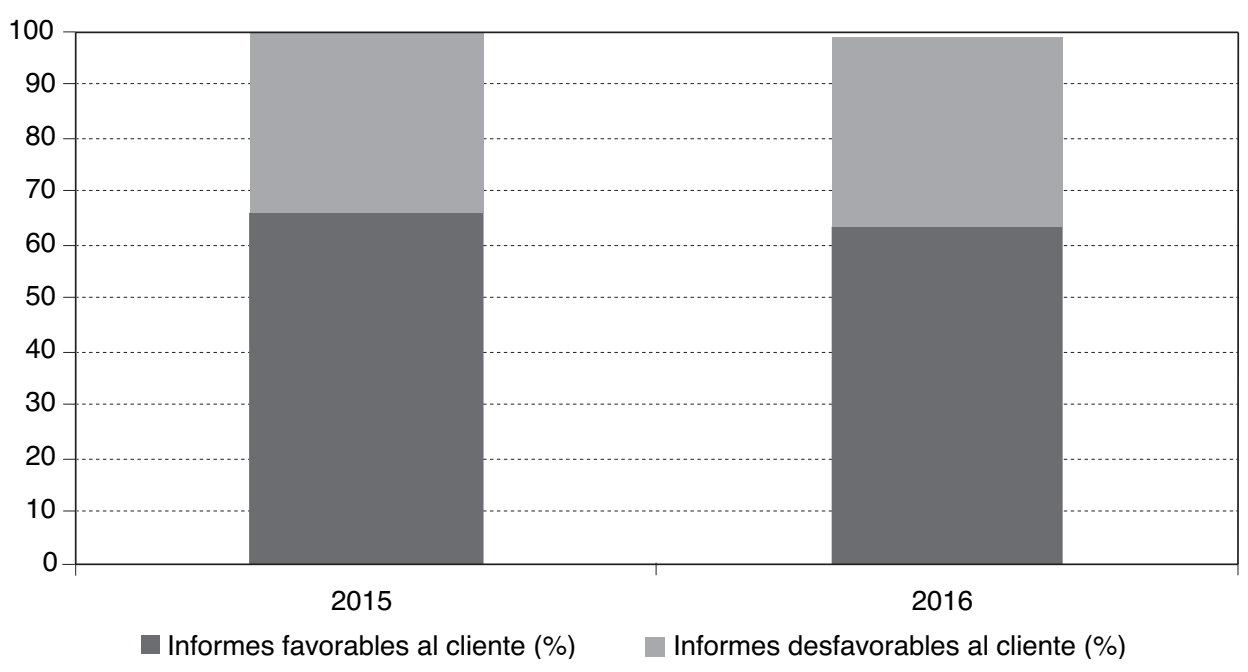

FUENTE: Elaboración propia a partir de datos del Banco de España (2015a).

protección de deudores hipotecarios sin recursos ${ }^{6}$. Este real decreto se publicó con la intención de paliar parte de las consecuencias negativas derivadas de la crisis que azotó nuestro país. Sin ánimo de extendernos en el contenido propiamente dicho del $\mathrm{CBP}^{7}$, simplemente nos gustaría analizar el grado de compromiso y de aplicación de estas medidas por parte del conjunto de entidades bancarias españolas. El Gráfico 3 muestra datos sobre el volumen de reclamaciones presentadas en relación a la aplicación del CBP a lo largo del primer semestre de 2016, tanto ante el SAC como el DC. En ambos casos observamos que la gran mayoría de las solicitudes se resuelven en contra de los argumentos del reclamante. Si se analizan los mismos datos referidos a las solicitudes tramitadas a través del DCMR (Gráfico 4) la situación es justamente la inversa. El cliente bancario cuando se dirige al DCMR obtiene una resolución favorable en el casi 83 por 100 de los casos, mientras que el porcentaje de resolución favorable solamente alcanza al 21 por 100 de los casos cuando son las entidades quienes atienden este tipo de reclamaciones, vía el SAC, y apenas alcanza el 1 por 100 cuando se dirigen al DC.

${ }^{6}$ El mencionado Real Decreto-Ley 6/2012 ha sido posteriormente modificado por la Ley 1/2013, de 14 de mayo, de medidas para reforzar la protección a los deudores hipotecarios, reestructuración de deuda y alquiler social, y el Real Decreto-Ley 1/2015, de 27 de febrero, de mecanismo de segunda oportunidad, reducción de carga financiera y otras medidas de orden social.

7 Normativa y requisitos que se deben cumplir para solicitar la aplicación del Código de Buenas Prácticas (http://www.mineco.gob.es/portal/site/mineco/menuitem.32ac44f94b634f76faf2b910026041a0/?vg nextoid $=$ d43ad0d172ff7310VgnVCM1000001d04140aRCRD\&vg). 


\section{GRÁFICO 3}

\section{RESOLUCIÓN DE RECLAMACIONES DE CLIENTES ANTE LAS ENTIDADES BANCARIAS EN LA APLICACIÓN DEL CBP (Primer semestre 2016)}

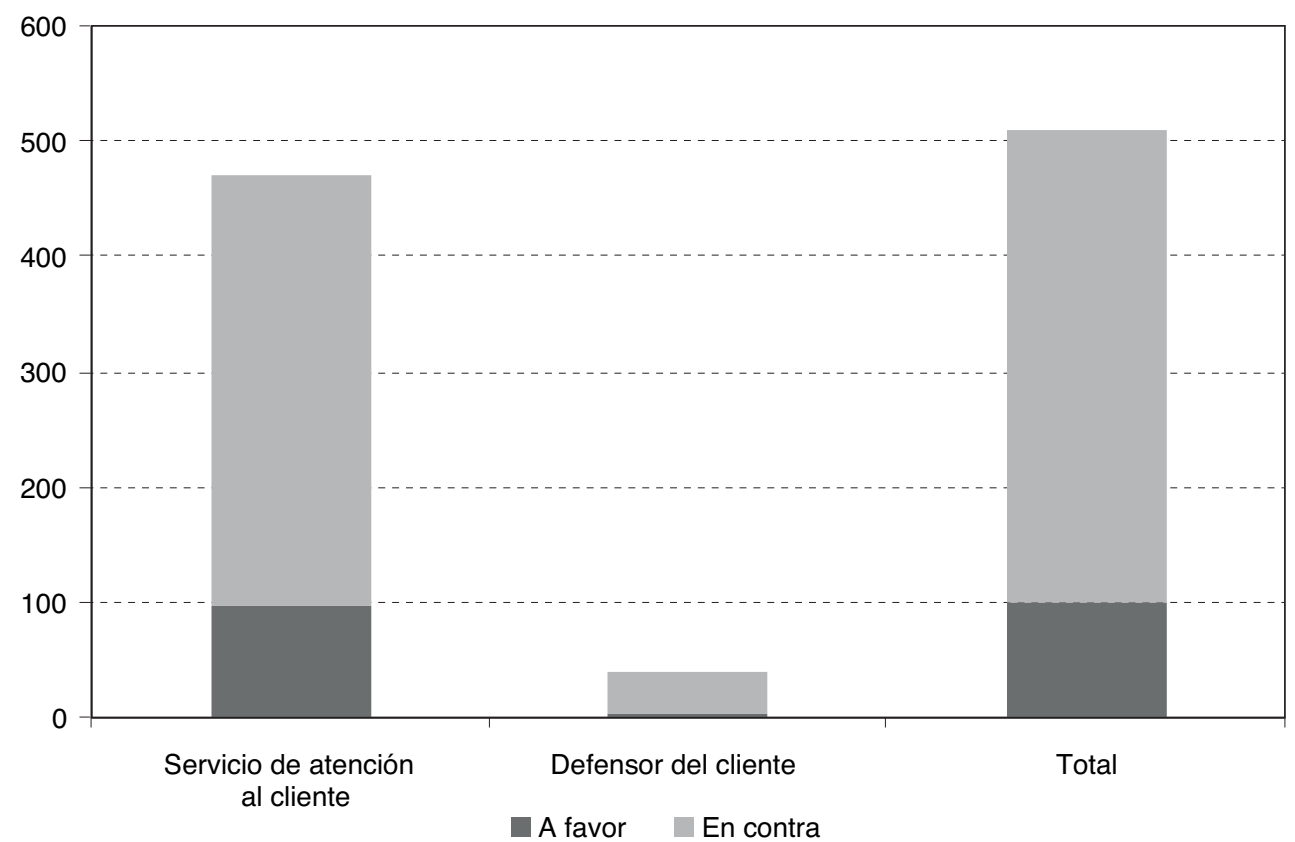

FUENTE: Elaboración propia a partir de datos del Ministerio de Economía, Industria y Competitividad (2016).

Esta realidad pone de manifiesto la situación de vulnerabilidad de los clientes bancarios cuando tratan de reivindicar sus derechos frente a las entidades bancarias.

Llegados a este punto la siguiente pregunta sería: ¿cómo se puede incentivar un comportamiento más responsable de las entidades bancarias con sus clientes? En el siguiente apartado trataremos de responder a esta pregunta.

\section{Importancia de la RSC en el negocio bancario}

A primera vista cuando analizamos el tipo de actividad que realizan los bancos, intermediación de flujos financieros entre oferentes y demandantes de recursos, puede parecer que esta actividad en sí misma no implica riesgos ambientales o sociales, y que las entidades bancarias son empresas de servicios «limpias» que se limitan a redistribuir dinero. No obstante, no es menos cierto que cuando un banco decide financiar un proyecto de inversión está haciendo partícipe de ese proyecto y de sus consecuencias e impactos a los accionistas y acreedores que han depositado su confianza y su dinero en él. De igual modo, cuando una entidad decide la oferta de productos y servicios bancarios que va a ofrecer a sus clientes esta operación no está 


\section{GRÁFICO 4 \\ INFORMES EMITIDOS POR EL DCMR EN RELACIÓN A LA APLICACIÓN DEL CBP}

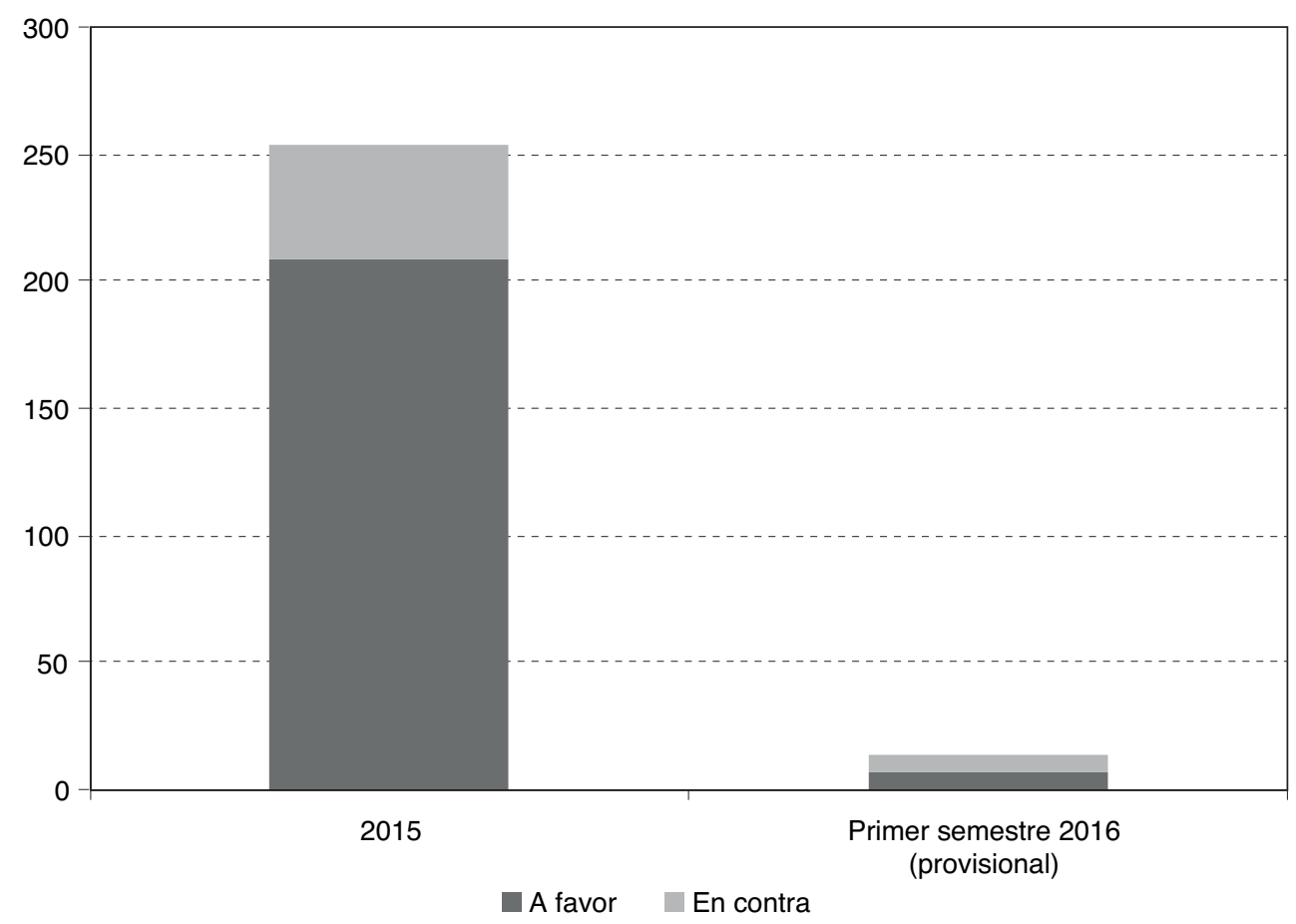

FUENTE: Elaboración propia a partir de datos del Ministerio de Economía, Industria y Competitividad (2016).

exenta de riesgos sociales y éticos. Por tanto, la influencia y responsabilidad de los bancos en la lucha contra la pobreza, el cambio climático, las desigualdades sociales y el desarrollo sostenible es cada día más importante.

El análisis de riesgos, función clásica de los bancos, no se limita a día de hoy a los riesgos financieros sino también a los riesgos que tienen que ver con el buen comportamiento y buen gobierno de las organizaciones. Teniendo en cuenta la última definición de 2011 sobre Responsabilidad Social Corporativa (RSC) de la UE, podríamos decir que una institución financiera es socialmente responsable si en su actividad de inversión, gestión de activos e intermediación financiera gestiona adecuadamente los riesgos, oportunidades, e impactos que dicha actividad tiene en la sociedad. Será socialmente responsable si se consideran cuestiones éticas y socioambientales, además de las económicas, en el diseño de los productos y servicios que ofrece, en su política de crédito e inversión y, en definitiva, en toda su estrategia del negocio, y también si cuenta con mecanismos de control (sistemas de evaluación de impacto, incentivos y sanciones, transparencia y rendición de cuentas, etc). 
Su función social es ofertar productos necesarios y de calidad a los ciudadanos en función de sus necesidades y no solo de los intereses de la dirección de la entidad. Evitar el riesgo legal de tener que compensar a los clientes por malas prácticas en el diseño y comercialización de productos no es solo una cuestión de interés general, sino de interés económico para la propia entidad. Y es ahí donde reside la auténtica responsabilidad social de la banca, en hacer bien su negocio.

Sin embargo, poca atención se ha prestado a esta visión comercial o de negocio de la RSC. Cuesta-González et al. (2006) ya proponían gestionar la responsabilidad social externa o comercial de la siguiente manera:

- Aplicando criterios de sostenibilidad a la financiación y aseguramiento bancario.

- Aplicando criterios de sostenibilidad a la gestión de activos y de inversión, fomentado lo que se denomina inversión socialmente responsable (ISR).

- Centrándose en un negocio de banca comercial o minorista más responsable con el cliente, no solo desde el punto de vista de la calidad, transparencia y honestidad, como señalan Pérez-Ruiz y Rodríguez-del Bosque (2012), sino poniendo el énfasis en conocer al consumidor y adaptar los productos, su coste y el canal de distribución a sus necesidades.

No obstante, la realidad es bien distinta y el comportamiento de las instituciones bancarias resultantes tras el proceso de reestructuración en España no ha estado exento de polémicas. Por un lado, hay que señalar los problemas que han experimentado las entidades bancarias en su modelo de negocio. A la creciente presión para reducir costes, en un contexto de márgenes de resultados ya de por sí muy reducidos, hay que sumar que se han tenido que enfrentar a la exigencia de unos mayores requisitos de capital regulatorio. Esta gran presión es el resultado de una filosofía de negocio basada en el principio de maximización de beneficios para el accionista en un horizonte a corto plazo (shareholder value maximisation).

Como resultado de estas presiones hemos presenciado comportamientos por parte de los gestores bancarios que podemos calificar de oportunistas, y que han desencadenado importantes problemas de naturaleza ética. Entre otros, podemos citar la importante evasión fiscal a través de paraísos fiscales; la incorrecta aplicación de códigos de conducta a la hora de detectar operaciones de corrupción, soborno, malversación de fondos o enriquecimiento indebido por parte de sus directivos, el blanqueo de capitales, la manipulación en el cálculo de las principales referencias de tipo de interés y de tipo de cambio, la concesión de préstamos sin los debidos controles de riesgo, la inclusión de cláusulas suelo y cláusulas de resolución anticipada de contratos abusivas en operaciones de préstamo hipotecario y la venta de instrumentos financieros inadecuados al perfil del inversor, como han sido las participaciones preferentes, entre otros.

Además del conflicto ético en sí mismo, este tipo de actuaciones ha tenido consecuencias jurídicas de gran calado puesto que, como ya se ha señalado, en el ámbito 
de la Unión Europea el Tribunal de Justicia se ha pronunciado sobre el contenido de dichas cláusulas ${ }^{8}$.

Dicho todo lo anterior, podemos afirmar que a día de hoy las entidades bancarias están atravesando una crisis de reputación sin precedentes en nuestro país. Para paliar las graves consecuencias que está ocasionando, las entidades son cada vez más conscientes de la importancia de su responsabilidad social como elemento de mejora de su reputación corporativa. La función de los bancos ya no se limita a intermediar flujos financieros gestionando adecuadamente los distintos riesgos financieros, sino que deben ser capaces de valorar y gestionar también un amplio espectro de riesgos sociales y medioambientales. La inadecuada gestión de los mismos no solo puede poner en entredicho la reputación de las entidades, sino que puede llegar incluso a poner en peligro la obtención de capital en los mercados financieros. Cada vez más, los grandes inversores institucionales exigen la valoración de este conjunto de riesgos en la gestión de carteras, puesto que el valor a largo plazo de los activos financieros está muy condicionado a la adecuada gestión de los mismos.

Gran número de estudios recientes han tratado de evaluar el impacto de la actividad bancaria en función de parámetros de RSC, pero en muchos casos se trata de meras aproximaciones. En el estudio de Fernández y De la Cuesta (2014) se analiza desde una perspectiva empírica la realidad de la RSC en 50 entidades bancarias europeas y se observa una dualidad muy marcada en términos de responsabilidad comercial o externa, es decir, sobre sus clientes, productos y servicios. El estudio concluye que los resultados obtenidos son dispares en función del modelo de negocio considerado en cada caso. Así, la banca líder en RSC en el negocio de banca comercial se caracteriza por estar formada por entidades de reducido tamaño, tener sus orígenes en un modelo de banca social y dedicarse, fundamentalmente, al negocio minorista de intermediación. Por su parte, las grandes entidades con clara vocación de banca universal son las que arrojan peores resultados en términos de RSC. Esta conclusión resulta relevante si tenemos en cuenta que la tendencia actual en España es hacia la concentración en entidades de mayor tamaño, la pérdida de peso de la banca relacional y la casi desaparición de la denominada de banca social (cajas de ahorro y cooperativas de crédito).

El Observatorio de RSC (2015) publica datos sobre las principales entidades bancarias de nuestro país y, en concreto, nos permite obtener información sobre un aspecto muy concreto de la RSC vinculado, precisamente, a su relación con clientes como uno de sus principales stakeholders. A la vista del Gráfico 5 podemos concluir que de todas las entidades bancarias consideradas en el estudio ninguna de ellas obtiene una puntuación superior a 2 (un 1,47 de media), lo cual significa que según los datos analizados en 2014 el compromiso de las entidades bancarias en su faceta de RSC de consumo se califica como «escasa». En términos de RSC global (Gráfico 6) que incluyendo, además, medio ambiente, derechos humanos

8 Vid. Asunto C-421/14, Banco Primus c. Jesús Gutiérrez, García, Sentencia del Tribunal de Justicia (Sala Primera), de 26 de enero de 2017. 


\section{GRÁFICO 5}

LA RESPONSABILIDAD SOCIAL CORPORATIVA DE CONSUMO DE LAS ENTIDADES BANCARIAS ESPAÑOLAS

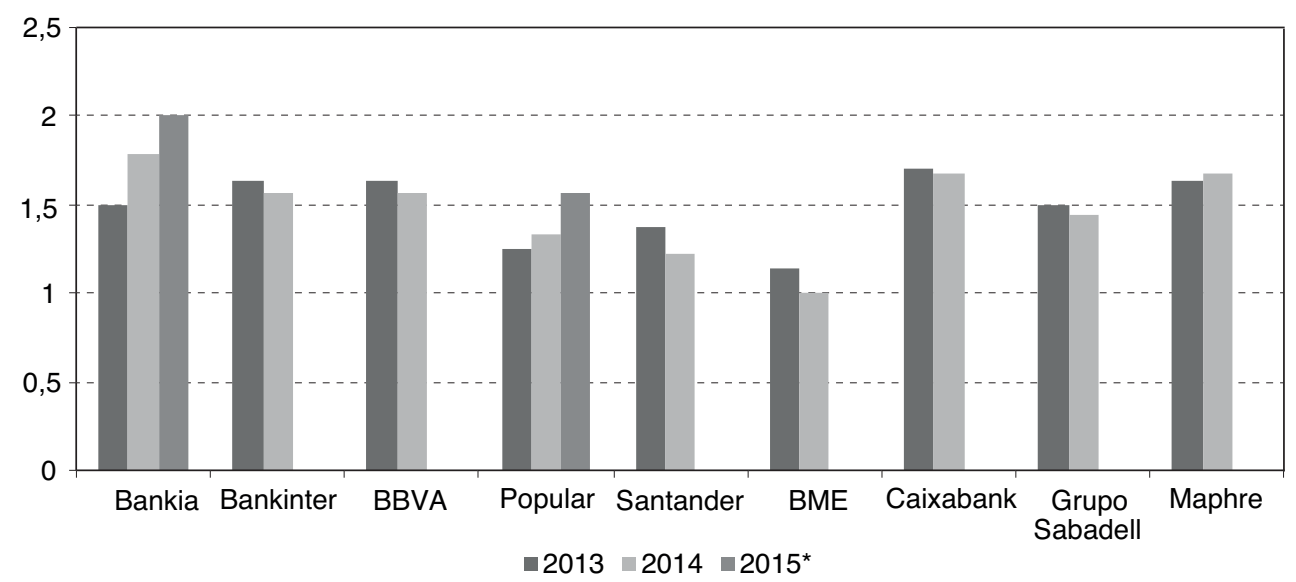

NOTA: Estimaciones provisionales.

FUENTE: Elaboración propia a partir de datos del Observatorio de RSC (2015).

\section{GRÁFICO 6}

\section{LA RESPONSABILIDAD SOCIAL CORPORATIVA GLOBAL DE LAS ENTIDADES BANCARIAS ESPAÑOLAS}

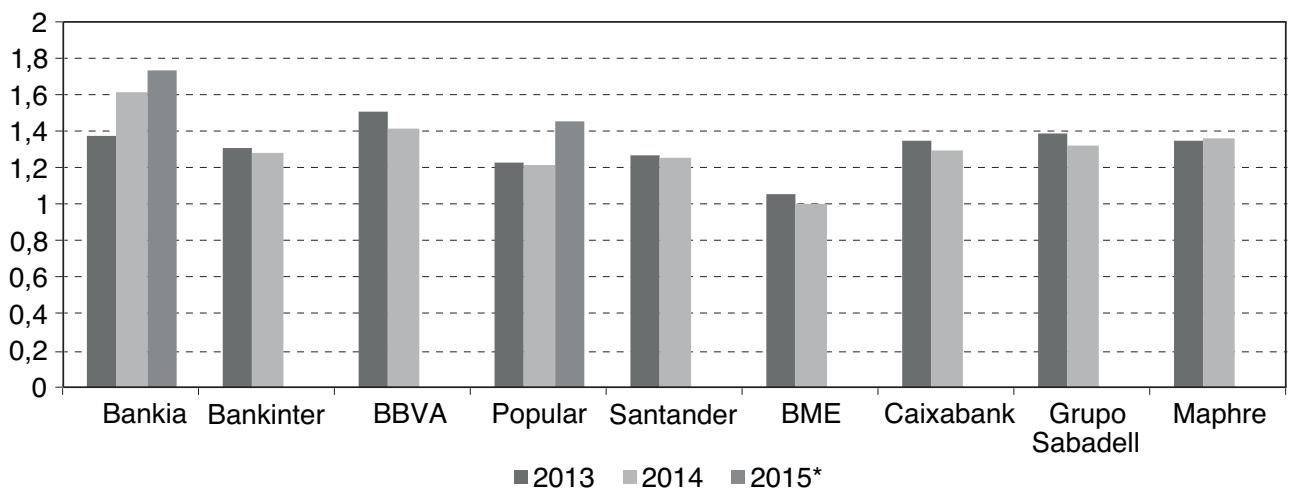

NOTA: Estimaciones provisionales.

FUENTE: Elaboración propia a partir de datos del Observatorio de RSC (2015).

y laborales, comunidad, corrupción y calidad de la información, la calificación media obtenida es aún más baja (1,3 según el último dato disponible). Los únicos datos disponibles para 2015 para Bankia demuestran que esta entidad continúa avanzando en la dirección correcta. En el caso del Banco Popular, a pesar de los datos positivos obtenidos por el Observatorio de RSC correspondientes al año 2015, en 2017 hemos asistido a la venta de la entidad al Banco Santander por un 
valor simbólico de un euro, a fin de evitar su caída y el efecto de contagio sobre el resto del sistema financiero.

\section{Retos y oportunidades}

Desde el ámbito académico se está tratando de impulsar la adopción de buenas prácticas en el negocio bancario en línea con los principios de RSC, principalmente en su responsabilidad social comercial (Pérez-Ruiz y Rodríguez del Bosque, 2012). Entre las principales líneas principales de actuación recomendadas destacamos tres:

- La inclusión de criterios de impacto ambiental y social en el diseño de productos financieros, así como en la estrategia de negocio y en la propia gestión de riesgos.

- Poner el énfasis en el cliente y en un modelo de negocio de banca más relacional.

- Minimizar los problemas de exclusión financiera y social mediante la universalización de servicios financieros, pero sin obviar le necesidad de adecuar cada producto y servicio financiero al perfil concreto del cliente.

Dentro de la primera línea de actuación se ha insistido en la necesidad de incrementar el volumen de préstamos en aquellos sectores o ramas de actividad que generen un mayor impacto social. Entre otros ejemplos podemos citar proyectos educativos, culturales y sociales, así como la financiación de microempresarios, emprendedores y pyme. Se trataría, al igual que ocurre con las inversiones socialmente responsables, de aplicar criterios positivos (de inclusión) y negativos (de exclusión) a determinados sectores/actividades. Si bien ya hay algunas iniciativas en este sentido, aún queda mucho camino por recorrer.

Poner al cliente en el centro de atención significa volver a un modelo de banca más relacional y personalizada (Maudos, 2015). Con la ayuda de la tecnología, como señala García Montalvo (2014), los bancos tienen acceso a grandes cantidades de datos que pueden ayudarles a ofrecer productos y servicios personalizados para cubrir las verdaderas necesidades financieras de sus clientes. Conviene evitar el uso de información de forma estandarizada y no personalizada ya que los resultados se ha visto que no son buenos.

Universalizar y democratizar el acceso a los servicios financieros debe venir acompañado de un adecuado necesario asesoramiento. Se trata de fomentar una inclusión financiera responsable de los segmentos de población más vulnerables y desfavorecidos, tanto desde un punto de vista geográfico (determinadas áreas rurales desabastecidas de sucursales) como socioeconómico (áreas y zonas con un menor perfil de renta). No obstante, hay que salvaguardar que la inclusión financiera no se produzca a expensas de generar una espiral de endeudamiento que, a medio y largo plazo, no generaría sino mayores problemas de pobreza y exclusión. 
Como hemos visto en este artículo, los riesgos asociados a la responsabilidad del negocio bancario son relevantes por el impacto que tienen en el desarrollo socioeconómico. Creemos que es necesario analizar estas cuestiones desde un punto de vista más concreto y descender a la operativa diaria para encontrar las respuestas y soluciones más acertadas. Las políticas generalistas de educación financiera, de mayor transparencia y protección al cliente son políticas acertadas, pero no suficientes para prevenir problemas como el sobrendeudamiento, la colocación de productos inadecuados o la exclusión financiera.

La directiva europea The Payments Account Directive (European Union, 2014) ya recoge necesidades específicas en términos de inclusión financiera de personas vulnerables como el derecho a una cuenta básica con facilidades de pago que incluya servicios en línea sin coste o a precio razonable. Los reguladores nacionales deberán fijar qué se entiende por precio razonable.

Otras medidas que pueden también ayudar a mejorar la RSC en el negocio bancario, especialmente referidas al negocio de banca al por menor podrían ser:

- Favorecer la sencillez de los productos financieros de forma que sus condiciones sean comprensibles para el cliente medio. En aquellos casos en los que el nivel de educación financiera sea insuficiente se recomienda complementar su comercialización con un servicio de asesoramiento a la medida de cada cliente. Para ello resulta imprescindible el papel que desempeñan las sucursales y los propios gestores bancarios.

- Mejorar la calidad de información de los productos financieros que por sus especiales características puedan resultar complejos en cuanto a estructura y posibles resultados. Véase, por ejemplo, el caso de las participaciones preferentes por su falta de liquidez en el mercado o la contratación de seguros frente a posibles subidas de los tipos de interés en préstamos hipotecarios.

- Mejorar los procedimientos de resolución de quejas a nivel de cada entidad (SAC y DC), ya que es a donde el cliente bancario se dirige en primera instancia para presentar una reclamación bancaria. En segunda instancia, el cliente tiene el derecho de acudir al DCMRE, que será quién resuelva y emita un informe no vinculante.

- Adhesión a estándares de compromiso público como los Principios de Ecuador (Banco Mundial) establecidos para grandes proyectos de inversión a fin de introducir criterios de sostenibilidad en las decisiones de inversión de las entidades.

- Comercializar productos financieros con perfiles específicos de inversores. Se podrían citar, entre otros, los fondos de inversión éticos o ecológicos, los fondos de microfinanzas, energías renovables o cambio climático.

- Ejercer de forma responsable el activismo accionarial frente a las empresas participadas y en las que se ostenten derechos políticos para influir en la toma de decisiones. 
Para concluir, nos gustaría señalar que es la ciudadanía la que está ejerciendo un papel muy activo al exigir un mayor compromiso ético a las entidades bancarias desde una doble perspectiva; como titular de productos bancarios se preocupan cada vez más por el destino de sus ahorros, y como accionistas a la hora de ejercer un control más activo de los impactos de determinados comportamientos bancarios.

Por todo ello creemos que hemos iniciado una senda de cambios que en el futuro nos conducirá a la recuperación de la reputación del sector bancario como un elemento clave del buen funcionamiento de la economía. Para ello, hay que aprender de la historia reciente y adaptarse a un entorno lleno de nuevas oportunidades, para aquellas entidades que sepan posicionarse en un mapa financiero donde han surgido nuevos competidores y donde prevalecen nuevas reglas de juego.

\section{Referencias bibliográficas}

[1] BANCO DE ESPAÑA (2016). Memoria de la Supervisión Bancaria en España, Madrid.

[2] BANCO DE ESPAÑA (2015). Memoria de Reclamaciones, Madrid.

[3] DE LA CUESTA, M.; MUÑOZ-TORRES M. J. y FERNÁNDEZ-IZQUIERDO, M. A. (2006). "Analysis of Social Performance in the Spanish Financial Industry through Public Data. A Proposal». Journal of Business Ethics, 69, 289-304.

[4] EUROPEAN UNION (2014). Directive 2014/92/EU of the European Parliament and of the Council of 23 July 2014 on the comparability of fees related to payment accounts, payment account switching and access to payment accounts with basic features, Official Journal of the European Union, 28th August 2014.

[5] EUROSIF (2016). European SRI study, Madrid. Recuperado 20 de febrero de 2017 de http://www.eurosif.org/wp-content/uploads/2016/11/SRI-study-2016-HR.pdf.

[6] FERNÁNDEZ OLIT, B. y DE LA CUESTA GONZÁLEZ, M. (2014). «Evaluación de impactos ambientales y sociales del negocio de banca comercial en Europa durante el periodo 2006-2010». Estudios de Economía Aplicada, 32-2, 567-592.

[7] GARCÍA-MONTALVO, J. (2014). «Back to boring banking in the age of deleveraging and new financial regulation». Spanish Economic and Financial Outlook, 3 (1), $5-15$.

[8] MAUDOS, J. (2015). «Retos del sector bancario español tras la reestructuración», Cuadernos de Información Económica, 249, noviembre, 11-25.

[9] MINISTERIO DE ECONOMÍA, INDUSTRIA Y COMPETITIVIDAD (2016). VIII Informe de la Comisión de Control sobre el Cumplimiento del Código de Buenas Prácticas para la Reestructuración Viable de las Deudas con Garantía Hipotecaria sobre la Vivienda Habitual, Madrid.

[10] OBSERVATORIO DE RESPONSABILIDAD SOCIAL CORPORATIVA (2015). «La responsabilidad social corporativa en las memorias anuales de las empresas del IBEX 35», Colección de Estudios del Observatorio.

[11] PÉREZ-RUIZ, A. y RODRÍGUEZ DEL BOSQUE, I. (2012). «La imagen de responsabilidad social corporativa en un contexto de crisis económica: El caso del sector financiero en España», Universia Business Review, primer trimestre, 14-29. 
[12] PRIOR, F. y ARGANDOÑA, A. (2009). «Best Practices in Credit Accessibility and Corporate Social Responsibility in Financial Institutions». Journal of Business Ethics, 87, 251-265.

[13] WUA, M. W. y SHEN, C. H. (2013). «Corporate social responsibility in the banking industry: Motives and financial performance». Journal of Banking \& Finance, 37, 35293547. 